\title{
A Construtura A CAMinho DA ESCOLA
}

\author{
The Constructure on its way to school
}

\author{
Suzete de Paula Bornatto*
}

\begin{abstract}
RESUMO
A coleção "Nossa Língua”, para $5^{\mathrm{a}}$. a $8^{\mathrm{a}}$. série do $1^{\circ}$. grau, é analisada como parte do grande empreendimento dos professores Eurico Back e Geraldo Mattos para a renovação do ensino de português no Brasil nos anos 70. Comercializados nacionalmente pela editora FTD, os livros tinham uma seção de "Gramática Complementar" com os conceitos fundamentais da "Gramática Construtural da Língua Portuguesa”, publicada por ambos na mesma época. "Nossa Língua” significou, assim, uma tentativa - fracassada - de divulgar essa nova teoria e sua nomenclatura. Analisada em comparação com suas contemporâneas, a coleção revela-se inovadora ao pleitear um ensino "sem gramática", mas também conservadora, ao defender um padrão de língua arcaizante - exercitado ao longo de muitos exercícios estruturais. A existência dessa obra, assim como a descontinuidade de sua publicação, interessam à história da disciplina - e da educação - por enriquecerem nossa perspectiva sobre o passado.
\end{abstract}

Palavras-chave: Livro didático; história da disciplina; ensino de português.

\begin{abstract}
The collection "Our Language" - aimed at students from the 5 th. to the 8th. grades of Junior High - is analyzed as part of the larger enterprise put forth by Professors Eurico Back and Geraldo Mattos for reconceiving the teaching of Portuguese in Brazil in the nineteen seventies. Nationally marketed by publisher FTD, the books had a section on "Supplementary

* UFPR
\end{abstract}


Grammar" with the fundamental concepts of "Constructural Grammar of the Portuguese Language", published by both authors at the same time. "Our Language" meant, in this way, an (unsuccessful) attempt to publicize that new theory and its terminology. Taken in comparison with its contemporary alternatives, the collection proves to be innovative in proposing the teaching "without grammar", but it is also conservative to the extent it upholds a archaic standard for language - put forth through many structural exercises. The existence of this work, as well as the discontinuation of its publication, are of great interest to the history of the discipline - linguistics and education - because they enrich our perspective of the past.

Keywords: Textbook; history of the discipline; Portuguese teaching.

\section{INTRODUÇÃo}

Em outubro de 2012, durante o I Seminário de Pesquisa sobre Livros Didáticos de Língua Portuguesa, em São Paulo, um debatedor envolvido com o PNLD - Programa Nacional do Livro Didático - lamentou, um pouco constrangido, que o sofisticado sistema de avaliação dos livros escolares, tanto pelas editoras como pelas equipes coordenadas pelo Ministério da Educação (MEC) resultasse, no final, em falta de inovação: para se adequarem e receberem o aval do Programa, as coleções seguem mais ou menos o mesmo script - e nenhum autor (ou editora) se atreve a propor algo diferente, o que seria financeiramente arriscado.

Embora os programas de avaliação de livros didáticos não sejam novidade, o controle editorial hoje é evidentemente maior. Mesmo na década de 40, quando a Comissão Nacional do Livro Didático - instituída em 1938, sob o Estado Novo - julgava a conformidade ideológica dos livros escolares, os autores tinham autonomia para propor enfoques e métodos diferenciados. Tal liberdade prosseguiu nos anos 50; é significativo que em 1959 o MEC tenha publicado a NGB - Nomenclatura Gramatical Brasileira, com o objetivo de estabelecer para as gramáticas e livros escolares uma terminologia única, evitando a criação e a mistura de conceitos e classificações. A iniciativa da NGB, porém, não impediu que, nos anos 60 , com o desenvolvimento dos estudos linguísticos, algumas coleções didáticas adotassem novas teorias como referência e, assim, outras nomenclaturas.

Segundo Faraco (2008), o ensino de português no Brasil foi alvo de uma crítica bastante específica até meados do século XX; não se condenava propriamente o ensino da gramática - "que foi sempre elemento central da 
tradição escolar brasileira" - mas seus defeitos. Os críticos atacavam em especial a obsessão do erro, a ênfase na terminologia e não nos fatos e o excesso de formalismo da análise sintática tradicional. Nas décadas seguintes, contudo,

foi o ensino da gramática em si que passou a ser objeto de condenação, em particular no início dos anos 1970. Alguns eventos daquele período favoreceram essa condenação - de um lado, a consolidação da linguística como matéria universitária e, de outro, a euforia com a chamada era da comunicação, combinada com o imediatismo do pensamento pedagógico tecnicista, que era privilegiado pela tecnoburocracia do regime militar (FARACO, 2008, p. 186).

A pedagogia tecnicista, para Faraco, queria uma escola enquadrada por parâmetros de produtividade fabril e que não perdesse tempo com o que se considerava supérfluo, ou seja, a educação humanística tradicional. Assim, "defendia-se uma pseudomodernização dos temas e dos procedimentos de ensino com ênfase na eficácia imediata da comunicação". Embora boa parte dos livros didáticos, segundo ele, tenha substituído a gramática por conceitos da teoria da comunicação, "o ensino de gramática continuou a ser feito regularmente nas escolas - até mesmo por inércia porque, tradicionalmente, sempre se identificou, no Brasil, o ensino do português com o ensino da gramática" (FARACO, 2008, p. 187).

A entrada da linguística nos cursos de Letras foi bem-vinda, mas logo houve quem quisesse defendê-la de maus usos. Gomes de Matos (MATOS, 1978, p. 51), tratando da influência da linguística em livros de português, diz que "alertara em 1972 para o uso indevido do nome da linguística por parte de alguns autores (a minoria) de livros didáticos" e para a necessidade de orientação dos professores a fim de não se deixarem iludir pela terminologia linguística ou pelo sentido promocional com que a ciência era, às vezes, utilizada.

De modo geral, os livros de português da primeira metade da década de 60 tinham textos, tópicos de gramática normativa e exercícios, além de temas e/ou modelos para redação. Materiais da CADES (Campanha de Aperfeiçoamento e Difusão do Ensino Secundário) já autorizavam, contudo, alguma mudança de prioridades. Ainda que o programa de português de 1951 já preceituasse que fossem evitadas a memorização de listas e definições e a abundância de termos técnicos e complicações inúteis, em 1961, o "Roteiro de Português" de El-Jaick é mais enfático: "Ensinar língua não significa ensinar gramática. [...] Não se aprende a língua memorizando regras, terminologia, formas e exceções" (EL-JAICK, 1961, p. 5). "Ensine menos gramática, para ensinar mais a língua” (EL-JAICK, 1961, p. 19). 
Ao contrário das Portarias anteriores, que detalhavam conteúdos por série, a Lei de Diretrizes e Bases de 1961 estabeleceu apenas orientações curriculares para o português, assegurando "plena liberdade aos autores de livros didáticos". Era um período de expansão do acesso à escola (em 1950, apenas um quarto da população em idade escolar frequentava a escola; em 1970 , o percentual ultrapassou os 50\%), e as editoras, muitas vezes subsidiadas pelo governo, modernizavam seus parques gráficos ${ }^{1}$ e investiam pesadamente na produção de livros didáticos.

Foi nesse contexto favorável, portanto, que Eurico Back e Geraldo Mattos, ambos com experiência no ensino básico e no ensino superior, publicaram, entre 1972 e 1974, um conjunto de livros que compuseram um programa completo para a escolarização básica: "Nossa casa: alfabetização pelo processo genético" (pré-escolar), "Nossa Gente - comunicação e expressão" ( $1^{\mathrm{a}}$. a $4^{\mathrm{a}}$. série) e "Nossa Língua" (5 . a $8^{\mathrm{a}}$.); Mattos é autor único da coleção "Nossa Cultura", para o $2^{\circ}$. grau, e Back assina "Formação e Evolução da Cultura", para o mesmo público, todos pela editora FTD, dos Irmãos Maristas. Lançaram também em 1974 "Prática de Ensino de Língua Portuguesa", completando seu projeto com uma proposta de formação para o professor.

No conjunto de ações voltadas à mudança no ensino de português, teve seu papel também a "Construtura - Revista de Linguística, Língua e Literatura" , criada em 1973 na Universidade Católica do Paraná sob direção de Geraldo Mattos (então chefe do Departamento de Letras). O periódico serviu como veículo de divulgação e defesa do Construturalismo, ao abordar seus fundamentos científicos e sua aplicabilidade didática (no n. 2, por exemplo, se trata de "Construturalismo e Didática"; no n. 8, há um plano de unidade de trabalho para a $6^{a}$. série). Além de artigos científicos e resenhas, alguns textos da revista respondem diretamente a críticas dirigidas ao Construturalismo.

A proposta deste artigo é apresentar a coleção "Nossa Língua", situando-a em relação a outros livros didáticos do período, a fim de evidenciar seu caráter programático e sua singularidade para a história da disciplina.

1 Em 1966, foi criada a COLTED - Comissão Nacional do Livro Técnico e Didático, dentro dos acordos de colaboração MEC-USAID e com a colaboração do Sindicato dos Editores (SNEL); em 1968, cerca de 60 editoras são responsáveis por aproximadamente 2500 títulos didáticos para os três níveis de ensino.

2 A revista começa com quatro edições anuais e número irregular de artigos. Em 1975, saem dois números, sob direção de Roberto Gomes, editados pela própria universidade. Em 1976, a Fundação Cultural de Curitiba é coeditora e a Comissão de Redação, composta por três professores (Mattos, Back e Orlando Bogo), se torna um Conselho Editorial com mais seis nomes. Três números depois, no entanto, noticia-se que a Fundação Cultural não honrou sua parte no acordo, por isso os autores ficaram sem pagamento. Em 1979, saem três números - sob um Conselho Editorial novamente reduzido - incluindo o $19^{\circ}$, que é o último, com três artigos. O fim da revista coincide, portanto, com a ida de Geraldo Mattos para a UFPR. 
Na história do ensino de Português, os debates sobre leitura, escrita e gramática, que configuram o movimento interno da disciplina, são tão relevantes quanto os de caráter metodológico desenvolvidos no âmbito das teorias psicológicas sobre a aprendizagem. Os anos 60 foram o momento da entrada da linguística como disciplina nos cursos de Letras (embora não houvesse suficientes doutores para ensiná-la), mas também das teorias behavioristas de aprendizagem, em especial das ideias de Skinner, que deram aos materiais escolares um ar de renovação.

A coleção "Nossa Língua", contudo, não apenas assume um novo pressuposto sobre a aprendizagem, como propõe um novo modelo de ensino de português, em que a Construtura se torna referência teórica para o ensino fundamental.

\section{UMA COLEÇÃO DIFERENTE?}

O estudo de coleções da segunda metade da década de 60 ajuda a situar o lugar ocupado por "Nossa Língua". "Português através de textos", de Magda Soares, apesar de ser talvez a primeira a incluir a palavra "texto" em seu título, é organizada a partir de tópicos gramaticais - o texto serve ao ensino da teoria sobre morfologia e sintaxe. Por exemplo, o sumário da $7^{\text {a }}$. série (GUIMARÃES, 1968, p. 3) está assim organizado:

I - ANÁLISE SINTÁTICA: ESTRUTURA DO PERÍODO COMPOSTO.

a) COMPOSIÇÃO DO PERÍODO.

texto: Ventania, Carlos Drummond de Andrade.

estudo do texto.

gramática.

b) PERÍODO COMPOSTO POR COORDENAÇÃO

$[\cdots]$

No Manual para os professores, a autora defende que a língua "é essencialmente instrumento de comunicação", e o objetivo primordial de seu ensino é o de aperfeiçoá-la e desenvolvê-la no educando como "meio de expressão e de compreensão de mensagens" (GUIMARÃES, 1967, p. 9, grifos do autor). Assim, o professor de língua será, "antes de tudo, um professor de comunicação", pois "é a comunicação que nos faz pessoas" (GUIMARÃES, 1967 , p. 10). O problema, segundo o texto, é que as mensagens imperfeitas são frequentes: "Comunicáveis e comunicantes que somos, quão imperfeitos ao comunicar!" (GUIMARÃES, 1967, p. 11). 
Essa exposição ilustra como, antes mesmo de a Lei 5.692/71 prescrever "especial relevo ao estudo da língua nacional, como instrumento de comunicação e como expressão da cultura brasileira”, essa perspectiva teórica já era assumida por estudiosos da didática da língua.

O "Estudo Dirigido de Português"3, de Mathias Ferreira (1967), anunciava na capa recursos lúdicos - "anedotas, palavras cruzadas, charadas, quebra-cabeças, curiosidades, [...]” - para conquistar um novo público, supostamente mais interessado em passatempos do que em textos literários. o estudo dirigido e as cruzadinhas não alteram, porém, o conteúdo: para preencher corretamente as lacunas horizontais e verticais, era preciso ter acertado, por exemplo, as respostas de um exercício de análise sintática ou fonológica.

Em livros do início dos anos $70^{4}$, como "Instrução programada de português" (MIRANDA, [197-]) e "Ensino programado de português" (FRANÇA, [197-]), superlativos e números ordinais são ensinados com "piadinhas". A ludicidade convive com o "tradicional": listas, nomenclatura, regras, análises. O objetivo principal continuava a ser que os alunos dominassem uma língua "formal".

Geraldo Mattos já havia publicado pela "Editora do Professor”, de Curitiba, os quatro volumes do "Curso da língua atual" (1967) - adotado no Colégio Estadual do Paraná - e, segundo seu depoimento, devido a essa experiência, Back teria dividido com ele a tarefa, proposta pela FTD, de uma nova coleção.

"Nossa Língua" teve circulação nacional e é ainda localizável em sebos de diversos estados do Brasil. As capas são coloridas e ostentam o título em vermelho sobre fundo branco com o formato do mapa do Brasil, além de versos de hinos oficiais (Hino Nacional, à Bandeira, da Independência, da República, do Soldado e também a Canção do Expedicionário).

Em sua primeira edição, os volumes são numerados de I a IV, porque pensados para as quatro séries do curso ginasial, mas no ano seguinte se adaptam à nova nomenclatura: $5^{\mathrm{a}}$. a 8 ${ }^{\mathrm{a}}$. série, já que a Lei 5.692/71 estende a obrigatoriedade do ensino, antes restrita aos quatro anos do curso primário, aos oito anos do $1^{\circ}$. grau.

Em cada volume há vinte lições, dez por semestre, e cinco extras, que poderiam ser usadas como prova. Os índices trazem três divisões: I Domínio da língua (lista com os títulos de 20 textos literários); II - Leitura suplementar (5 textos); III - Gramática complementar, com a teoria da gra-

3 Essa coleção foi assumida, no início dos anos 70, pela recém-criada Editora Ática, onde ganhou o trato editorial que a transformou em absoluto sucesso comercial, repercutindo na formatação de coleções posteriores.

4 Data presumida - muitas editoras evitavam registrar o ano da edição para que os livros se mantivessem "atuais" e vendáveis. 

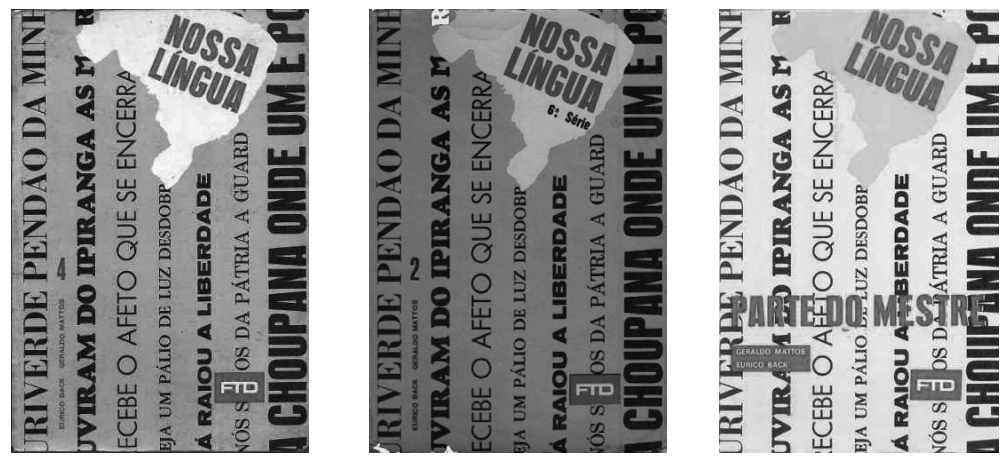

FIGURA 1 - CAPAS DE ALGUNS VOLUMES DA COLEÇÃO.

mática construtural, distribuída em 20 itens, em cerca de 90 páginas. Em todos os volumes, os itens progridem até chegar ao conceito de "construtura".

A seleção de textos não destoa das demais, nesse período em que os escritores vivos já tinham forte presença nos livros de escola. A função dos textos - ensinar ou ampliar vocabulário, testar a leitura, a compreensão (por meio, basicamente, da localização de informações e da ordenação lógica das informações lidas) - não difere da que desempenhavam em coleções anteriores. Na "Parte do mestre" que acompanha a coleção, definia-se que o texto, além de suporte para extração de informações, seria suporte analógico para a redação. De todo modo, a leitura não está aí apenas para o prazer ou pela exemplaridade; apesar de haver a exploração da "mensagem", os textos são utilizados também (ou principalmente) como fonte de estruturas linguísticas que serão treinadas.

Nas propostas de redação, "Nossa Língua" também não se destaca de suas contemporâneas. Há temas que podem ser debatidos, provérbios para serem explicados (uma tradição escolar de vários séculos), mas há também palavras motivadoras que deveriam ser transformadas em texto pelos alunos ("A dor", "A neve", "A tristeza", "O inverno").

Em relação ao ensino da língua, entretanto, os autores radicalizam a compreensão de que teoria gramatical, nomenclatura, regras não deveriam ser objeto de ensino. Eles sugerem que a gramática teórica não ocupe mais do que $20 \%$ de uma prova e que os exercícios, "baseados na instrução programada", sirvam como "estudo dirigido". Essa associação dos dois termos talvez não agradasse a especialistas como Amélia Castro, referência na área de didática desse início dos anos 70, para quem "trabalho dirigido" e "instrução programada" eram conceitos distintos, com propósitos e características próprias.

A "Parte do mestre" que acompanha "Nossa Língua" é um volume único para as quatro séries. Além das respostas das questões objetivas (95\% 
do total de questões), traz onze páginas sobre a "Genética da aprendizagem", desenvolvendo os conceitos de comunicação, cláusula comunicativa, atividades emissiva e receptiva, aprendizagem primitiva (associação, comparação, recorrência, criatividade) e sua aplicação específica no caso do ensino de português.

É nesse volume que os autores explicam ao "colega" professor seu projeto, propondo o rompimento com o passado do ensino de língua e a adoção da Gramática Construtural, que seria baseada em "provas científicas". A adoção não é obrigatória, mas essa nova teoria seria a única admissível. Assim, são apresentadas três opções de utilização do material com os alunos:

a) um curso de português sem gramática, seguindo em cada ano do item 1 ao item 6 de cada lição;

b) um curso de português com a nossa gramática, deixando uma aula por semana para a parte final do livro de cada série (se houver algum feriado na semana, deixar para ele a aula de gramática!!); c) um curso de português com a gramática tradicional (observação idêntica).

A primeira opção é a melhor e cremos que o colega há de saber preferi-la às outras, porque basta ao nosso aluno o sabimento (existe essa palavra?) da melhor técnica de falar e escutar, escrever e ler, acompanhada sempre do hábito de pensar seriamente (BACK; MATTOS, 1972c, p. 5).

Por que se dar ao trabalho de incluir nos livros um conteúdo que, na melhor opção, seria desconsiderado? Essas alternativas oferecidas ao professor explicitam uma prioridade que não era a tradição da disciplina: na primeira, ensinar sem gramática significava ensinar sem análises ou classificações, sem nomenclatura nem regras explícitas.

Escolhendo a segunda opção, o professor ingressaria no mundo novo e científico da Construtura, que se procurava divulgar; em último caso, se resistisse às duas anteriores, que usasse a gramática tradicional, mas reservasse para isso apenas uma aula por semana, no máximo.

A teoria e a nomenclatura da Gramática Construtural estavam, portanto, em "Nossa Língua", mas apenas para o professor que quisesse ensiná-las. Nos diversos exemplares da coleção consultados em Curitiba (entre 2007 e 2009), todos com marcas de uso, os capítulos referentes à Construtura não tinham qualquer anotação ou exercício resolvido.

Além da fundamentação teórica distinta, os autores tentam também propagar novos usos - de início, um novo sentido para o uso duplicado dos pontos de exclamação e de interrogação: dois pontos de interrogação para pontuar perguntas cuja resposta pode ser "sim" ou "não", e dois pontos de 
exclamação para marcar uma ordem a cumprir, distinguindo assim a ordem das simples exclamações. Se pensarmos nas inúmeras turmas de professores de português que tiveram Back e Mattos como formadores, é possível imaginar que essas pequenas (e ingênuas) criações fossem também ensinadas, na esperança de que se tornassem usuais.

Por outro lado, algumas orientações metodológicas são mais objetivas: o professor é orientado a fazer estatística dos erros mais frequentes dos alunos para combatê-los sistematicamente; no $1^{\circ}$. grau, o professor não devia falar nunca em substantivos, pronomes, em fato gramaticais, mas somente levar os alunos a falar e escrever corretamente através de exercícios construturais (BACK; MATTOS, 1972c, p. 15). Além disso, não devia nunca fazer testes de gramática, perguntando o que é verbo, pronome, mandando sublinhar os verbos, pedindo análise sintática, a não ser para testar a si mesmo, se a sua aula foi clara, mas não para dar nota. A justificativa para isso é que

As gramáticas que existem, são contraditórias; não têm nenhuma base científica, são falsas suas conceituações, falsas em suas regras, e tremendamente incompletas, confusas. [...] enquanto não tivermos um levantamento das linguagens regionais, com suas variantes (ou "erros") não é possível estabelecer uma sequência rigorosamente científica de programa (BACK; MATTOS, 1972c, p. 20).

Para um professor que desconhecesse a Gramática Construtural, havia pouca esperança de fundamentação consistente, já que as demais gramáticas eram portadoras de falsidade, contradição, incompletude e confusão. Havia clareza da necessidade de pesquisa das "linguagens regionais" e da relativização dos "erros", mas isso ainda era tarefa por fazer.

De fato, Aryon Rodrigues (2002, p. 15) reconhecia em 1968 que quase tudo o que vinha sendo escrito sobre língua padrão (ou norma linguística) no Brasil estava "prejudicado por uma atitude normativa e muito subjetiva", que procurava impor à sociedade um padrão, em lugar de procurar descobrir o padrão, ou os padrões naturalmente constituídos na sociedade. Quanto à relação professor-aluno, Back e Mattos também têm sugestões:

Se queremos formar novos hábitos em nossos alunos, o melhor meio é a amizade, o incentivo, o elogio, a alegria pelo progresso diário, aulas e trabalhos motivados e interessantes, não a ameaça, a tirania, o castigo (BACK; MATTOS, 1972, p. 22). 
Há, portanto, o movimento de recusa à tradição gramatical, que é um componente específico da disciplina de Português, por falta de cientificidade e de verdade, mas também a rejeição ao modelo pedagógico do professor tirano, que não interage convenientemente com os alunos e não os motiva. A preocupação com a motivação está presente em coleções como as de Magda Soares e Mathias Ferreira, em parte fundamentadas na teoria da comunicação e na pedagogia renovada; "Nossa Língua", porém, estabelece uma relação direta entre a metodologia de ensino da língua e a (des) motivação dos alunos. Ao propor uma gramática nova em substituição à tradicional, contudo, se revela contraditória, como discutirei adiante.

Os exercícios "sem gramática" são de imitação de modelos. Por exemplo, no volume para $5^{\mathrm{a}}$. série (BACK; MATTOS, 1973a, p. 59):
6.12. Siga o modelo:
a) Conhecemo-los
- Nós os conhecemos.
b) Vimo-lo.
c) Vemo-los
d) Amamo-la.
e) Conhecemo-las.

Nesse volume, uma nova terminologia aparece aos poucos, antes da parte complementar de gramática. Por exemplo, "vestígio" é um termo técnico que serve ao conjunto teórico proposto, então o professor deve explicá-lo ao aluno. Os participantes da comunicação são comunicantes, de forma que em uma narrativa em que a mãe vela pelo sono do filho, "o menino é comunicante, embora dormindo" (BACK; MATTOS, 1973a, p. 84). Os autores indicam também novas definições para termos como sinédoque ("emprego do domínio pela matriz"), metáfora ("emprego de uma matriz por outra") e metonímia ("emprego da matriz pelo domínio"), forçando a adequação dos conteúdos à nova teoria.

As análises necessitam da terminologia própria da Construtura (período, cláusula, base, suplemento), como em "O nome do $1^{\circ}$. emissor está na base ou no suplemento do período?" (BACK; MATTOS, 1973a, p. 23), ou para entender uma estrutura como a seguinte (BACK; MATTOS, 1973a, p. 95):

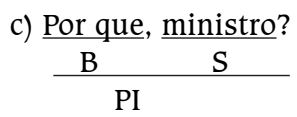


Em todos os volumes, se insiste na distinção entre linguagem coloquial (identificada com a cotidiana ou "descuidada") e adloquial (formal, "culta”). Esta seria menos comum, "mais elegante". São exemplos da linguagem adloquial que os alunos poderiam identificar e treinar no volume II, de 6a. série (BACK; MATTOS, 1972a):

\author{
Eu me não humilho diante de ninguém. (p. 7) \\ Custa caro ler cousas agradáveis? (p. 29) \\ Tirou-lhe o livro?? \\ - Tirou-mo, sim. \\ Mandou-me alguma notícia?? \\ - Mandou-lha, sim. (p. 47)
}

No volume para $7^{\mathrm{a}}$. série (BACK; MATTOS, 1973b, p. 13) lemos que "a linguagem adloquial não admite variante do pronome no início de período. [...] Se você acha que a expressão ('empresta-me o livro') é muito dura, pode fugir colocando outras palavras no início: "Você me empresta??".

Em todas as unidades há exercícios de transformação, outros do tipo "siga o modelo", associação ou preenchimento de lacunas - exercícios que se popularizam a partir da década de 70 . As flexões de número e gênero, bem como a formação do superlativo são treinadas repetidamente. Assim, o aluno aprenderia por repetição, por exemplo, o feminino e o plural de "aldeão" (de frequência duvidosa na fala dos adolescentes), além dos superlativos "salubérrima", "frigidíssima", "tetérrimo5" (BACK; MATTOS, 1973b, p. 112).

A explicação teórica da gramática complementar usa anedotas e pequenas histórias redigidas pelos autores, que servem para uma analogia com o conceito que se quer explicar. Por exemplo, "a família tem construção e estrutura: é uma construtura." (BACK; MATTOS, 1973b, p. 129). Depois da explicação, há uma série de testes e exercícios. No volume IV (BACK; MATTOS, 1972b, p. 172), se pede que o aluno pegue uma revista em quadrinhos - não para se divertir, mas para aprender sobre "fator", "decorrente" e "situação".

"Nossa Língua", ainda que fosse portadora de uma nova teoria gramatical, continuava fiel ao mesmo modelo, à língua "da escola". Certamente, a maioria dos alunos não saiu da escola escrevendo "cousas" como "mandou-lha" nos anos 70. São expressões que mais parecem o "outro" português a que se refere Drummond em seu poema "Aula de português".

5 O superlativo de "tétrico" aparece também nos exercícios da "Instrução Programada", de França. Apesar da insistência, um exemplar usado de "Nossa Língua" traz na p. 77 a resposta "tetriquíssima" corrigida como certa. 
Que língua era essa que se procurava identificar como "nossa"? Que utilidade teria o aprendizado sobre cláusulas e períodos, de uma terminologia exclusiva dessa coleção?

O FRACASSO FAZ PARTE DA HISTÓRIA

Não há ainda resultados de pesquisa sobre a participação de Back e Mattos na elaboração de documentos oficiais do estado do Paraná, mas algumas pistas indicam que tiveram uma influência importante.

Em documento curricular da Secretaria de Estado da Educação de 1972, eles são a principal referência, ao lado de Colin Cherry, que fundamenta a análise do "fenômeno da comunicação"; não se fala, porém, em Construtura. No texto, após um diagnóstico de mudanças na constituição familiar e de falta de diálogos produtivos entre pais e filhos, os modernos recursos da propaganda são acusados pela descaracterização dos relacionamentos pessoais; a escola, para resistir a isso, deveria passar a constituir "uma agência de comunicação".

No final dos anos 80, Faraco (1988) se refere ao "método" de Back como um "pacote metodológico":

Nos anos 70, ficou famosa, ao menos no Paraná, a "linha" ou o método do prof. Eurico Back. Seus livros didáticos tiveram grande sucesso e venderam muito bem. Ele transformou-se numa espécie de missionário de uma cruzada antigramatical, percorrendo o Estado, com apoio oficial, para divulgar seu "método".

Do mesmo modo que se espalhou como fogo em campo seco, esse pacote logo caiu em descrédito, fracassando como proposta, embora tivesse levantado certas alternativas concretas para o ensino de Português (FARACO, 1988, p. 74).

É importante destacar a análise de que os livros tiveram "grande sucesso" - o que talvez fosse devido à atuação dos autores nos cursos de Letras (da Universidade Católica e da UFPR), mas também "apoio oficial". As "alternativas concretas" levantadas, porém, não garantem a continuidade da obra: "Nossa Língua" só teve duas edições (1972 e 1973).

Infelizmente, a editora não disponibilizou registros sobre o número de exemplares vendidos - sob alegação de sigilo comercial; é queixa comum dos pesquisadores do mercado editorial, aliás, a ausência de registros ou a pouca vontade de divulgá-los. De qualquer modo, a FTD continuou publicando obras de Back (preparação para concursos e ensino de literatura) e Mattos 
(livros para todos os níveis, incluindo uma nova gramática, sob o pseudônimo de M. dos Santos), mas sem referências à Construtura - e investiu em novas coleções, como a de Tescarolo e Megale - "Novos caminhos em comunicação e expressão" -, com os conteúdos gramaticais de sempre.

o bordão do ensino "sem gramática", entretanto, subsistiu. Nos "Guias Curriculares para o ensino de $1^{\circ}$. grau" do estado de São Paulo, publicados um pouco mais tarde, em 1975, a proposta e a justificativa não eram muito diferentes:

Não é a gramática normativa que ensina língua, mas sim a própria língua. Diante disso, ensinar língua é ensinar através de exercícios de língua (exercícios estruturais, de análise, de síntese, de classificação, de relacionamento, de transformações), para que o aluno se habilite a usar a língua para a produção e compreensão de frases (SÃO PAULO, CERHUPE, 1975, p. 18, apud ANGELO, 2006, p. 67).

Mesmo assim, a análise de coleções dos anos 70 mostra que a teoria da comunicação não expulsou a gramática normativa, apenas compartilhou o espaço e ganhou evidência nos títulos. Aliás, quarenta anos depois, em tempos que supostamente privilegiam a leitura e a escrita, a teoria e a nomenclatura da gramática tradicional continuam ocupando espaço (demais) nos livros didáticos.

\section{Considerações Finais}

A produção de livros escolares por professores universitários constitui uma tradição importante na história da educação brasileira e explicita uma face da sempre debatida relação entre universidade e escola. Ainda que a publicação dos livros atenda a interesses diversos e raramente represente um projeto institucional, essas obras levam temas, escolhas e abordagens do meio acadêmico para a escola.

Como, porém, a escola tem papel ativo na definição e fixação de conteúdos de ensino, conforme defendem Chervel $(1990,2006)$ e Batista (1997), os projetos vindos da academia podem não ter o impacto esperado. A Construtura no ensino é um caso de insucesso, mas que ajuda a entender a dinâmica da história da disciplina.

Conforme Diana Vidal (2005, p. 132), que estudou o fracasso da estenografia como solução para o ensino da escrita na escola primária francesa, "o estudo do insucesso de alguns projetos convida a não apenas 
explorar as condições históricas de seu aparecimento, sua genealogia, mas propicia o destaque de irregularidades, índices de contradições na paisagem aparentemente homogênea do ontem". Em relação aos livros de português, Batista (1997) faz referência a dois casos de insucesso de livros que procuraram "incorporar resultados da pesquisa linguística e foram um fracasso de vendas": "Tempo de comunicação", de Ada Rodrigues e outros, e "Português: treinamento e criatividade", de Milton Nascimento e outros.

As generalizações sobre os livros dos anos 70 no Brasil, embora ofereçam muitas pistas sobre o momento e as tendências da produção didática, não são suficientes para enquadrar essas coleções, e é isso que as torna interessantes para a história.

A contradição do projeto de "Nossa Língua", que talvez tenha contribuído para inviabilizá-lo comercialmente, foi a intenção de defender, ao mesmo tempo, o ensino sem gramática e uma nova teoria gramatical - que pretendia renovar a compreensão da língua, mas ajudava a cristalizar um padrão desatualizado. O mercado (isto é, professores, escolas, pais) parece ter aprovado os exercícios, a metodologia, mas rejeitou o Construturalismo como referência teórica, recusou a substituição da "gramática tradicional" por essa sem nenhuma tradição, embora mais "científica".

Em outro momento da história dos livros didáticos de português no Brasil, Carlos Alberto Faraco e David Mandryk (1980), dois ex-alunos de Eurico Back, lançam uma obra inovadora em relação à inserção da linguística no ensino: "Português Atual - Leitura e redação". O livro resulta de material trabalhado pelos autores junto a públicos diversos (alunos de $2^{\circ}$. grau e ingressantes em cursos superiores). Além de exercícios mais complexos de análise dos textos (retirados principalmente de jornais e revistas), de reescrita de períodos e parágrafos, tem seis capítulos tematizando a língua - entendida já como um conjunto de variedades.

$\mathrm{Na}$ apresentação, os autores explicam: "Não há aqui nenhuma preocupação em apresentar teoria gramatical. Damos - isto sim - grande ênfase a exercícios práticos com a língua portuguesa e a exercícios de reflexão sobre a estrutura da língua" (FARACO; MANDRYK, 1980, p. 7). Apenas nos apêndices do final aparecem tópicos sobre, por exemplo, ortografia e pontuação. A proposta de "Português Atual" se diferencia muito da de outras obras do período; ao desvincular, porém, o aprendizado da escrita do conhecimento da teoria gramatical, preserva um pouco da ousadia que estava em "Nossa Língua" e que permanece motivo de polêmica, trinta anos de estudos linguísticos depois. 


\section{FONTES}

BACK, E.; MATTOS, G. Livro II. São Paulo: FTD, 1972a.

; _ Livro IV. São Paulo: FTD, 1972b.

;___ Parte do mestre. São Paulo: FTD, 1972c.

;___ Nossa língua. 5a. série. São Paulo: FTD, 1973a.

;__ . . . $7^{a}$. série. São Paulo: FTD, 1973b.

FARACO, C. A.; MANDRYK, D. Português atual - leitura e redação. Petrópolis: Vozes, 1980.

FERREIRA, R. M. Estudo dirigido de português. 4ª série. São Paulo: FTD. 1967.

FRANÇA, A. L. Ensino programado de português. São Paulo: Ed. do Brasil, [197-].

GUIMARÃES, M. S. Português através de textos. $3^{\text {a }}$. série. 1. ed. Belo Horizonte: Editora Bernardo Álvares, 1968.

. Manual do professor. (1 $1^{\mathrm{a}}$. e $2^{\mathrm{a}}$. séries). Belo Horizonte: Bernardo Álvares, 1967.

MATTOS, G.; BACK, E. Prática de ensino de língua portuguesa. São Paulo: FTD, 1974.

MATTOS, G. Curso da língua atual. Curitiba: Editora do Professor, 1967.

MIRANDA, J. F. Instrução programada de português. [s.l.]: Ed. do Brasil, [197-].

\section{REFERÊNCIAS}

ANGELO, G. L. O que dizem alguns documentos oficiais sobre o ensino tradicional de língua portuguesa. ICLAFPL, 2006. Disponível em: < http://www.cce.ufsc.br/ clafpl/7_Graziela_Angelo. pdf > . Acesso em: 30/1/2013.

BATISTA, A. A. G. Aula de português - discurso e saberes escolares. São Paulo: Martins Fontes, 1997.

CHERVEL, A. História das Disciplinas Escolares: reflexões sobre um campo de pesquisa. Teoria e Educação, Porto Alegre, v. 2, p. 177-229, 1990.

. Histoire de l'enseignement du français du XVIIe au XXe siècle. Paris: Retz, 2006.

EL-JAICK, J. Roteiro de português. Rio de Janeiro: Ministério da Educação e Cultura/CADES, 1961.

FARACO, C. A. Concepção de linguagem e ensino de português. Revista Escola Aberta, Curitiba, ago. 1988.

. Norma culta brasileira: desatando alguns nós. São Paulo: Parábola Editorial, 2008.

MATOS, F. G. Influência da linguística em livros de português. Tempo Brasileiro, Rio de Janeiro, v. 53/54, 1978.

RODRIGUES, A. D. Problemas relativos à descrição do português contemporâneo como língua padrão no Brasil. In: BAGNO, M. Linguística da norma. São Paulo: Edições Loyola, 2002. p. 11-23.

VIDAL, D. G. Culturas escolares - Estudo sobre práticas de leitura e escrita na escola pública primária (Brasil e França, final do século XIX). Campinas: Autores Associados, 2005.

Submetido em: 23/05/2013

Aceito em: 18/07/2013 